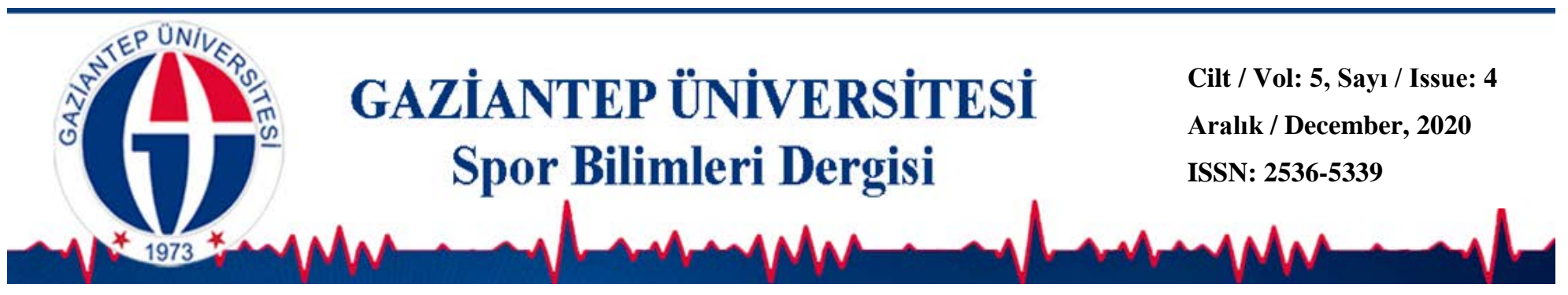

\title{
Sporcuların ve E-spor Oyuncularının Dijital Oyun Bağımlılığı ve Dijital Oyun Bağımlıı̆ı̆ına İlişkin Farkındalık Düzeyleri
}

\author{
Hasan Ceyhun CAN ${ }^{1 *}$ Gönül TEKKURŞUN DEMIR ${ }^{2}$ (D) \\ ${ }^{1}$ İstanbul Üniversitesi Cerrahpaşa, Spor Bilimleri Fakültesi, ISTANBUL \\ ${ }^{2}$ Gazi Üniversitesi Spor Bilimleri Fakültesi, ANKARA
}

DOI: 10.31680/gaunjss.770600

Orijinal Makale / Original Article

Geliş Tarihi / Received: 17.07.2020 Kabul Tarihi / Accepted: 06.10.2020 Yayın Tarihi / Published: 14.12.2020

Öz

Günümüzde dijitalleşmenin yaygınlaşması sonucu dijital oyun bağımlılığı sorunu baş göstermiştir. Bu bağlamda araştırmada sporcuların ve e-spor oyuncularının dijital oyun bağımlılığı ve dijital oyun bağımlılığına ilişkin farkındalık düzeyinin incelenmesini amaçlamıştır. Araştırmada tarama modelinden ilişkisel tarama modeli kullanılmıştır. Araştırmaya günde en az 30 dakika bir e-spor oyununu oynayan ve haftada en az 2 gün spor yapan 61 sporcu, 80 e-spor oyuncusu katılmıştır. Veri toplama aracı olarak, Akın, Usta, Başa ve Özçelik'in (2016) Türkçeye uyarladığı Oyun Bağımlılığı Ölçeği (OBÖ) ile Demir ve Cicioğlu'nun (2020) geliştirdiği Dijital Oyun Bağımlılığına İlişkin Farkındalık Ölçeği (DOBíF̈) kullanıımıştır. Verilerin analizinde Pearson Spearman Korelasyon, Mann-Whitney U Testi, Kruskal-Wallis Testinden yararlanılmıştır. OBÖ ve DÖBİÖ puanları arasında negatif yönde yüksek düzeyde anlamlı ilişki saptanmıştır. Dijital oyun bağımlılığı puanının erkek e-spor oyuncularının lehine anlamlı farklııı gösterdiği saptanmıştır. Sporcuların yaşı ile OBÖ arasında pozitif yönde orta düzeyde, DÖBIFÖ puanı arasında negatif yönde orta düzeyde anlamlı ilişki bulunmuştur. Zararlı alışkanlığa sahip olma durumuna göre OBÖ ve DOBIFÖ arasında anlamlı farklılık saptanmamıştır. Katılımcıların günlük dijital oyun oynama süresi ile OBÖ ve DOBIFÖ puanları arasında anlamlı farklılık tespit edilmiştir. Araştırma sonucunda, espor oyuncularının sporculara göre yüksek düzeyde oyun bağımlıığına sahip olduğu ve oyun bağımlılığına ilişkin farkındalıklarının sporculardan daha yüksek olduğu tespit edilmiştir.

Anahtar Kelimeler: Spor, Sporcu, E-spor, Dijital Oyun Bağımlılığı, Dijital Oyun Bağımlılığına İlişkin Farkındalık

\section{Digital Gaming Addiction and Awareness Levels Regarding Digital Gaming Addiction of Athletes and E-sports Players}

\section{Abstract}

Lately the issue of digital gaming addiction has arisen due to the widespread of digitalization. In this context, this study aims to evaluate the digital gaming addiction and the awareness levels regarding digital gaming addiction in athletes and e-sports players. In this research, relational screening was used as the research method. 80 e-sports players who play an e-sport game at least 30 minutes a day and 61 athletes who train at least 2 times a week participated in the study. As data collection tools, we used Gaming Addiction Scale (GAS), which was adapted to Turkish by Akın, Usta, Başa and Özçelik (2016) and Awareness of Digital Game Addiction Scale (ADGAS) which was developed by Demir and Cicioğlu (2020). Pearson Spearman Correlation, Mann-Whitney U Test and KruskalWallis Test were utilized to analyze the obtained data. The study finds highly significant negative correlation between GAS and ADGAS scores. Digital gaming addiction scores demonstrate significant difference in favor of male e-sports players. The study shows medium level positive significant correlation between the ages of the athletes and GAS scores while demonstrating medium level negative significant correlation regarding age and ADGAS scores. The study does not find any significant difference in terms of having harmful habits and GAS and ADGAS scores. Findings demonstrate significant difference between daily gaming time and GAS and ADGAS scores. The study concludes that e-sports players have higher level of gaming addiction along with higher awareness regarding gaming addiction in comparison to athletes.

Key Words: Sports, Athlete, E-sports, Digital Gaming Addiction, Awareness Regarding Digital Gaming Addiction

\footnotetext{
* Sorumlu Yazar: Hasan Ceyhun CAN
}

E-mail: ceyhuncan@istanbul.edu.tr 


\section{Giriş}

Teknoloji ve internetin çağımız içerisinde hızla gelişim ve değişim göstermesiyle birlikte bireylerin hayatında büyük değişimler gerçekleşmiştir. Bireylerin hayatındaki bu değişimler zamandan ve ekonomiden tasarruf edebilmeleri, sağlıktan eğitime, eğlenceden ulaşıma birçok alanda etkili olmuştur (Sağlık Bakanlığı, 2018; Can ve Tozoğlu, 2019). Teknolojinin etki ettiği alanlardan bir tanesi de oyun olmuştur. Oyun, geleneksel formundan günümüze kadar insanın yaşamının bir parçası olmuştur. Teknoloji ve internet gibi çağımızın önde gelen unsurlarının da etkisiyle, alışılagelmiş şeklinde çeşitli değişikliklere uğramıştır. Bu değişiklikler sonucunda gelişen teknoloji adeta oyun oynama aracı olarak kullanılmış ve neredeyse oyun davranışı boş vakitlerde en çok tercih edilen davranış halini almıştır.

Her işin temelinde oyunun var olduğu söylenebilir (Huizinga, 2018). Hatta çocukların beslenmeden sonraki en temel ihtiyaçlarının başında oyun gelmektedir (Gökşen, 2014). Kendinden güçlü hayvanları ve doğa olaylarını taklit etmesiyle günümüze dek uzanan oyun olgusu, bazen belli kurallar çerçevesinde, bazen de kural olmaksızın ortaya çıkmaktadır (Demir ve Cicioğlu, 2020). İnsanlık tarihiyle eşdeğer görülen bu davranış, her çağda ve her yerde kendi kendine ya da başkalarıyla uygulanan; eğitim, yaratıcılık, hayal, taklit ve iletişim açısından varlığını sürdüren önemli bir etkinliktir (Ayhan ve Çavuş, 2014). Sokak oyunları ya geleneksel oyun olarak adlandırılan bireylerin zihinsel ve fiziksel gelişimine yardımcı olan, eğlenerek öğrenilmesini sağlayan, doğal oyun ortamından bireyler gün geçtikçe uzaklaşmakta ve yerine teknolojik araçlarla, kapalı mekânlarda daha hareketsiz oyun oynamayı tercih etmektedirler (Tuğrul, 2015; Demir ve Cicioğlu, 2020; Demir ve Bozkurt, 2019). Tercih edilen bu oyunlar, dijital oyunlar olarak adlandırılmakta ve en genel manada teknolojinin oyun amaçı olarak kullanılması olarak tanımlanmaktadır (Marsh, Plowman, Yamada-Rice, Bishop ve Scott, 2016). Geleneksel oyun türlerinin karşısında konumlandırılmakta olan (Mustola, Koivula, Turja ve Laakso, 2016) ve teknolojinin getirilerini sonuna kadar kullanan dijital oyunlar yaşantımızın önemli bir parçası haline gelmiş (Güvenli İnternet Merkezi [GiM], 2019; Namlı ve Demir, 2020) dahası bu oyun türleri çocuklar tarafından ilk fırsatta yapılacak aktivite olarak görülmeye başlamıştır (Hazar ve ark., 2017). Öyle ki bir çalışma çıktısına göre çocuklardan oyun kavramını tanımlamaları istendiğinde, tamamına yakınının dijital oyuna yönelik benzetmelerde bulunduğu tespit edilmiştir. Buradan hareketle, 
çocuklar için oyun kavramının yerini dijital oyunun aldığı söylenebilir (Yaşar, 2019). Genel olarak dijital oyunlar, bireylerin dikkatini ve enerjisini gerçek yaşam sorunlarından ve stresten uzaklaştırmak için benzersiz başa çıkma stratejileri sunmaktadır (Kneer ve ark., 2014). Ülkemizde yaklaşık 30 milyon insan bilgisayarların, telefonların ve televizyonların karşısında oyun oynamaktadır (GIM, 2019). Bu durum dijitalleşen oyunlara ne kadar rağbet gösterildiğini yansıtmaktadır. Öyle ki dijital oyunlar, günümüz dünyasında dijital yerli olarak adlandırılan yeni neslin en önemli uğraşlarından birisi haline gelmiştir (Demir ve Hazar, 2018).

Gelişen bu teknolojinin insan yaşamına kazandırdığı kolaylıklar yanında, dijital araçlar üzerinde yapılan çalışmalarda görüldüğü üzere aşırı kullanılmaları durumunda bireye farklı şekillerde zarar verebilecek bağımlılık durumu ortaya çıkabilmektedir (Arslan, 2019). Bağımlılık, alışkanlık yaratan bir maddenin sürekli kullanımı sonucunda kişilikte ve davranışlarda sağlıkı kişilerde gözlemlenmeyen olumsuz davranışların ortaya çıkması, bilişsel algılamanın zarar görmesi, iradenin engellenmesi şeklinde belirtileri görülen hastalık olarak adlandırımaktadır (Campbell, 2003). Bağımlıık, kişinin alışkanlık yaratacak bir şeyi, bir kez kullanması, bu kullanımı tekrarlaması, zararları akabinde bir süre ara vermesi, bu zararları unutması durumunda yeniden kullanmaya başlaması ile farkında olmadan bağımlıık sürecine girmesiyle sonuçlanan bir durumdur (Tarhan ve Nurmedov, 2011). Bir bağımlılık türü olarak bilgisayar bağımlılığı ya da internet bağımlılığı (Young, 2009) başlığı altında değerlendirilen dijital bağımlıı̆ı kavramı, bireyin bilgisayar, internet, telefon, televizyon, tablet, sosyal medya vb. teknolojiye yönelik ortamlarla olan ilişkisini tanımlamak için kullanılmaktadır (Shaw ve Black, 2008; Young, 2009; Yang ve Tung, 2007). Dünya Sağlık Örgütü'ne (WHO) göre dijital oyun bağımlılığın bir hastalık olarak kabul edilmiştir. Fakat bireylerin bunun bir hastalık olduğunun bilincine varması, oyun oynama saatini kontrol etmesi, aşırı oyun oynayıp oynamadığını fark etmesi için dijital oyun bağımlıı̆ı̆na ilişkin farkındalıklarının olmasını gerekmektedir (Demir ve Cicioğlu, 2020). Farkındalık yargılamadan ve beklentiye girmeden beliren, kişinin dikkatini bulunduğu zaman dilimine çeken dikkat etme, dikkat kesilme dizisidir (Ford, 2016). Farkındalık düzeyi yüksek bireyler içinde yaşadığı durumu bilir, anlar ve olduğu gibi kabul eder (Brown, Ryan ve Creswell, 2007).

Dijital oyunlar alanında ülkemizde ve dünyada çeşitli bilinçlendirme çalışmaları mevcuttur (GIM, 2019). Gençlik ve Spor Bakanlığı'nın 40 bin gence eğitim hizmeti 
sunduğu 'farkındayız' isimli projesinde, dijital olumsuz içeriklerle alakalı farkındalığın arttııımasına yönelik çalışmalarda bulunmuştur (Kibar, 2019). Dijital oyunların, eğitim-spor amaçlı kullanılması, fiziksel aktiviteden uzaklaşma, şiddet ve beslenme bozukluğuna neden olması gibi pek çok konu ile ilişkisinin geniş yelpazede incelenmesi gerekmektedir. Oyunların bağımlılık yapıcı etkisi göz önüne alındığında, bireyleri dijital oyunların taşıdığı risklerden korumak adına, dijital oyunlar alanında bilinçlendirme çalışmalarına intiyaç duyulmaktadır (Yalçın Irmak ve Erdoğan, 2016). Bireyin dijital oyun bağımlıı̆ı̆ından korunması için bireyin dijital oyun bağımlıığına ilişkin farkındalık düzeyi önemli bir unsurdur. Düzenli olarak spor yapan ve düzenli olarak e-spor oyunu oynayan sporcu ve e-spor oyuncularının dijital oyun bağımlıı̆ının tespit edilmesi ve dijital oyun bağımlılığına ilişkin farkındalık düzeyi ile ilişkilendirilmesi önemlidir.

$\mathrm{Bu}$ bağlamda araştırmada sporcu ve e-spor oyuncularının dijital oyun bağımlıı̆̆ı ve dijital oyun bağımlıı̆̆ına ilişkin farkındalık düzeyinin çeşitli değişkenlere göre incelenmesi amaçlanmıştır.

\section{Yöntem}

Bu bölümde araştırmanın modeline, çalışma grubuna, veri toplama araçlarına ve verilerin analizine yer verilmiştir.

\section{Araştırma Modeli}

Araştırmada çok sayıda elemandan oluşan bir evrende evren hakkında genel bir yargıya varmak amacı ile evrenin tümü ya da ondan alınacak bir grup örnek ya da örneklem üzerinde yapılan genel tarama modelinden iki ya daha çok değişken arasında birlikte değişim varlığını veya derecesini belirlemeyi amaçlayan ilişkisel tarama modeli kullanılmıştır (Karasar, 2011).

\section{Evren ve Örneklem}

Araştırmanın örneklem grubu sporcu ve e-spor oyuncusu bireylerden oluşmaktadır. Araştırma grubu, günde en az 30 dakika bir e-spor oyununu oynamak ve haftada en az 2 gün spor yapmak ölçütleri doğrultusunda oluşturulmuştur. Araştırmaya katılan sporcuların yaşları 22.08 \pm 2.66 , e-spor oyuncularının yaşları $22.76 \pm 4.39$ 'dur. Araştırmada belirlenen ölçütlere uymayan 57 
Can, H.C. ve Tekkurşun Demir, G. (2020). Sporcuların ve E-spor Oyuncularının Dijital Oyun Bağımlılığı ve Dijital Oyun Bağımlılığına İliş̧kin Farkındalık Düzeyleri. Gaziantep Üniversitesi Spor Bilimleri Dergisi, 5(4), 364-384.

katılımcının verileri çalışma dışı bırakıımıştır. Bu bağlamda araştırmaya 61 sporcu, 80 e-spor oyuncusu olmak üzere toplam 141 kişi katılmıştır.

\section{Verilerin Toplanması}

Araştırmada, araştırmacılar tarafından hazırlanan kişisel bilgi formunun yanı sıra iki adet ölçek formu kullanılmıştır. Bu ölçekler şunlardır:

Oyun Bağımııı̆̆ı Ölçeği (ОВÖ): Lemmens, Valkenburg ve Peter, (2009) tarafından geliştirilen Akın, Usta, Başa ve Özçelik (2016) tarafından Türkçeye uyarlanan tek alt boyuttan oluşan ölçek kullanılmıştır. Ölçek beşli likert tipinde bir ölçek olup 7 maddeden oluşmaktadır. Ölçeğe uygulanan doğrulayıcı faktör analizi sonucunda uyum indekslerinin kabul edilebilir arada oluğu saptanmıştır $\left(x^{2}=32.35, s d=23\right.$, RMSEA = .093, NFI= .95, CFI= .98, IFI=.97, CFI= .94, GFI= .94). Ölçeğin Cronbach alfa iç tutarlılık güvenirlik katsayısı ve.90 olarak bulunmuştur.

Dijital Oyun Bağımlıığına İlişkin Farkındalık Ölçeği (DOBiFÖ): Demir ve Cicioğlu (2020) tarafından geliştirilen ölçek 12 maddeden oluşmaktadır. Ölçek beşli likert tipinde bir ölçektir. Katılımcıların DOBİFÖ toplam puanının, 12-28 düşük, 29-44 orta, 45-60 olması yüksek düzeyde dijital oyun bağımlılığına ilişkin farkındalığa sahip olduğu şeklinde ifade edilir. Ölçeğe uygulanan doğrulayıcı faktör analizi sonucunda uyum indekslerinin kabul edilebilir arada oluğu saptanmıştır $\left(x^{2}=236.01, \quad s d=121\right.$, RMSEA= .081, NFI= .97, CFI= .97, IFI=.95, CFI= .96, GFI= .95). Ölçeğin Cronbach alfa iç tutarlılık güvenirlik katsayısı .93 olarak tespit edilmiştir.

\section{Verilerin Analizi}

Veriler herhangi bir analize tabi tutulmadan önce parametrik testlerin ön şartlarını sağlayıp sağlamadığı tespit edilmiştir. Bu bağlamda değişkenlere normallik testi ve varyansların homojenliği için "Kolmogorov-Smirnov Testi" ile "Levene Testi" kullanılmıştır. Bu testler sonucunda dağılımı \pm 1 aralığında olmayan, dağılımın normal olmadığı değişkenlere non-parametrik testler uygulanmıştır (Büyüköztürk, 2014). Verilerin analizinde Pearson Spearman Korelasyon, Mann-Whitney U Testi, KruskalWallis Testi kullanılmıştır. Mann-Whitney U Testi için "Z" dağılımı istatistiği, "KruskalWallis Testi için "Ki-Kare" dağılımı istatistiği dikkate alınmıştır. Analizlerde aritmetik ortalama $(\overline{\mathrm{x}})$, standart sapma (ss) değerlerinden yararlanılmıştır. Uygulanan istatistiki testlerde güven düzeyi .05 olarak esas alınmıştır. 


\section{Bulgular}

Tablo 1. Sporcuların ve E-spor Oyuncularının OBÖ ve DÖBIFÖ puanları

\begin{tabular}{llll}
\hline \multirow{2}{*}{ Sporcular } & & $\overline{\mathbf{x}}$ & ss \\
\hline \multirow{2}{*}{ E-spor oyuncuları } & OBÖ & 13.13 & 5.38 \\
\cline { 2 - 4 } & DÖBÏFÖ & 40.49 & 10.82 \\
\cline { 2 - 4 } & OBÖ & 21.21 & 7.70 \\
\cline { 2 - 4 } & DÖBIFÖ & 45.71 & 6.98
\end{tabular}

Tablo 1'de Sporcuların ve E-spor Oyuncularının OBÖ ve DOBIFÖ puanlarına ilişkin bilgiler yer almaktadır. Buna göre Sporcuların oyun bağımlılığı düzeylerinin $(\bar{x}=13.13 \pm 5.38)$ düşük, dijital oyun bağımlılığına ilişkin farkındalık puanlarının orta düzeyde ( $\bar{x}=40.49 \pm 10.82)$ olduğu saptanmıştır. E-spor oyuncularının oyun bağımlılığı düzeylerinin $(\bar{x}=21.21 \pm 7.70)$ orta, dijital oyun bağımlılığına ilişkin farkındalık puanlarının yüksek düzeyde $(\bar{x}=45.71 \pm 6.98)$ olduğu tespit edilmiştir.

Tablo 2. OBÖ ve DÖBiFÖ Iliş̧kisi

\begin{tabular}{lllll}
\hline & & & OBÖ & \multicolumn{1}{c}{ DÖBIFÖ } \\
\hline \multirow{3}{*}{ Sporcular } & OBÖ & $\mathrm{r}$ & 1.000 & $-.475^{\star \star}$ \\
& & $\mathrm{p}$ &. & .000 \\
\cline { 2 - 5 } & DÖBIFÖ & $\mathrm{r}$ & $-.475^{\star \star}$ & 1.000 \\
& & $\mathrm{p}$ & .000 &. \\
\hline \multirow{3}{*}{ E-spor oyuncuları } & OBÖ & $\mathrm{r}$ & 1.000 & $-.720^{\star \star}$ \\
& & $\mathrm{p}$ &. & .000 \\
\cline { 2 - 5 } & DÖBIFÖ & $\mathrm{r}$ & $-.720^{\star \star}$ & 1.000 \\
& & $\mathrm{p}$ & .000 &. \\
\hline
\end{tabular}

$\overline{\mathrm{p}<.05}$

Tablo 2'de Sporcuların ve e-spor oyuncularının Dijital Oyun Bağımlılığı ve Dijital Oyun Bağımlıığına İlişkin Farkındalık puanları arasındaki ilişkin tespit edilmesi amacıyla yapılan pearson spearman analizi yer almaktadır. Yapılan analiz sonucunda sporcuların OBÖ puanları ile DOBİÖ puanları arasında negatif yönde yüksek düzeyde anlamlı ilişki saptanmıştır ( $r=-.475$; $p<.05)$. E-spor oyuncuların OBÖ puanları ile DOBİFÖ puanları arasında da negatif yönde yüksek düzeyde anlamlı ilişki saptanmıştır ( $r=-.720 ; p<.05)$.

Tablo 3. Sporcuların ve E-spor Oyuncularının yaşları ile OBÖ ve DÖBİFÖ İlişkisi

\begin{tabular}{lllll}
\hline & & & OBÖ & DÖBiFÖ \\
\hline \multirow{2}{*}{ Sporcular } & Yaş & $\mathrm{r}$ & $.346^{\star \star}$ & $-.295^{\star}$ \\
\multirow{2}{*}{ E-spor oyuncuları } & & $\mathrm{p}$ & .006 & .021 \\
& Yaş & $\mathrm{r}$ & .106 & -.037 \\
& & $\mathrm{p}$ & .349 & .747 \\
\hline
\end{tabular}

$p<.05$ 
Tablo 3'te Sporcuların ve e-spor oyuncularının yaşı ile Dijital Oyun Bağımlıı̆̆ı ve Dijital Oyun Bağımlılığına İlişkin Farkındalık puanları arasındaki ilişkin tespit edilmesi amacıyla yapılan pearson spearman analizi görülmektedir. Sporcuların yaşı ile OBÖ puanı $(r=.346$; $p<.05)$ pozitif yönde orta düzeyde ve DÖBİFÖ puanı ( $r=-.295$; $p<.05)$ arasında negatif yönde orta düzeyde anlamlı ilişki tespit edilmiştir.

Tablo 4. Sporcuların ve E-spor Oyuncularının Cinsiyetleri ile OBÖ ve DÖBIFÖ Analizi

\begin{tabular}{|c|c|c|c|c|c|c|c|c|}
\hline & & Cinsiyet & $\mathbf{N}$ & $\begin{array}{l}\text { Sira } \\
\text { ortalaması }\end{array}$ & $\begin{array}{l}\text { Sira } \\
\text { toplamı }\end{array}$ & $\begin{array}{l}\text { Mann } \\
\text { Whitney U }\end{array}$ & Z & p \\
\hline \multirow{4}{*}{ Sporcular } & OBÖ & Kadın & 20 & 26.95 & 539.00 & \multirow{2}{*}{329.000} & \multirow{2}{*}{-1.248} & \multirow{2}{*}{.21} \\
\hline & & Erkek & 41 & 32.98 & 1352.00 & & & \\
\hline & \multirow[t]{2}{*}{ DOBIFÖ } & Kadın & 20 & 36.35 & 727.00 & \multirow[t]{2}{*}{303.000} & \multirow[b]{2}{*}{-1.646} & \multirow{2}{*}{.10} \\
\hline & & Erkek & 41 & 28.39 & 1164.00 & & & \\
\hline \multirow{4}{*}{$\begin{array}{l}\text { E-spor } \\
\text { oyuncuları }\end{array}$} & OBÖ & Kadın & 16 & 24.69 & 395.00 & \multirow[t]{2}{*}{259.000} & \multirow{2}{*}{-3.057} & \multirow{2}{*}{$.00^{*}$} \\
\hline & & Erkek & 64 & 44.45 & 2845.00 & & & \\
\hline & DOBİFÖ & Kadın & 16 & 50.44 & 807.00 & \multirow[t]{2}{*}{353.000} & \multirow{2}{*}{-1.917} & \multirow{2}{*}{.06} \\
\hline & & Erkek & 64 & 38.02 & 2433.00 & & & \\
\hline
\end{tabular}

Tablo 4'te sporcuların ve e-spor oyuncularının cinsiyetleri ile OBÖ ve DÖBİÖ puanları arasındaki farklılık Mann Whitney $U$ Testi ile incelenmiştir. Yapılan analiz sonucunda, e-spor oyuncularının OBÖ puanlarında cinsiyete göre anlamlı farklılık saptanmıştır. Buna göre erkek e-spor oyuncularının OBÖ düzeyleri, kadın e-spor oyuncularının OBÖ düzeylerinden anlamlı düzeyde yüksektir ( $Z=-3.057 ; p<.05)$.

Tablo 5. Sporcuların ve E-spor Oyuncularının Zararlı Alışkanlık Kullanımı ile OBÖ ve DÖBİFÖ Analizi

\begin{tabular}{|c|c|c|c|c|c|c|c|c|}
\hline & & $\begin{array}{l}\text { Zararlı } \\
\text { Alışkanlık }\end{array}$ & $\mathbf{N}$ & $\begin{array}{l}\text { Sıra } \\
\text { ortalaması }\end{array}$ & $\begin{array}{l}\text { Sıra } \\
\text { toplamı }\end{array}$ & $\begin{array}{l}\text { Mann } \\
\text { Whitney U }\end{array}$ & Z & p \\
\hline \multirow{4}{*}{ Sporcular } & \multirow[t]{2}{*}{ OBÖ } & Evet & 15 & 26.03 & 390.50 & \multirow{2}{*}{525.500} & \multirow{2}{*}{-1.032} & \multirow{2}{*}{.30} \\
\hline & & Hayır & 46 & 32.62 & 1500.50 & & & \\
\hline & \multirow[t]{2}{*}{ DOBİFÖ } & Evet & 15 & 31.23 & 468.50 & \multirow[t]{2}{*}{518.500} & \multirow{2}{*}{-1.107} & \multirow[b]{2}{*}{.26} \\
\hline & & Hayır & 46 & 30.92 & 1422.50 & & & \\
\hline \multirow{4}{*}{$\begin{array}{l}\text { E-spor } \\
\text { oyuncuları }\end{array}$} & \multirow[t]{2}{*}{ OBÖ } & Evet & 21 & 44.98 & 944.50 & \multirow[t]{2}{*}{270.500} & \multirow{2}{*}{-1.251} & \multirow{2}{*}{.21} \\
\hline & & Hayır & 59 & 38.91 & 2295.50 & & & \\
\hline & \multirow[t]{2}{*}{ DOBİFÖ } & Evet & 21 & 35.69 & 749.50 & \multirow{2}{*}{341.500} & \multirow{2}{*}{-.059} & \multirow{2}{*}{.95} \\
\hline & & Hayır & 59 & 42.21 & 2490.50 & & & \\
\hline
\end{tabular}

$\mathrm{p}<.05$

Tablo 5'te sporcuların ve e-spor oyuncularının zararlı alışkanlığa sahip olma durumu ile OBÖ ve DÖBIFÖ puanları arasındaki farklılık Mann Whitney U Testi ile incelenmiştir. Yapılan analiz sonucunda, sporcuların ve e-spor oyuncularının zararlı 
Can, H.C. ve Tekkurşun Demir, G. (2020). Sporcuların ve E-spor Oyuncularının Dijital Oyun Bağımlılığı ve Dijital Oyun Bağımlılığına İliş̧kin Farkındalık Düzeyleri. Gaziantep Üniversitesi Spor Bilimleri Dergisi, 5(4), 364-384.

alışkanlığa sahip olma durumu ile OBÖ ve DÖBİFÖ puanları arasında anlamlı farklılık saptanmamıştır ( $p>.05)$.

Tablo 6. Sporcuların ve E-spor Oyuncularının Günde Dijital Oyun Oynama Süresine Göre OBÖ DÖBiFÖ Analizi

\begin{tabular}{|c|c|c|c|c|c|c|c|c|}
\hline & & $\begin{array}{l}\text { Süre } \\
\text { (dakika) }\end{array}$ & Grup & $\mathbf{N}$ & $\begin{array}{l}\text { Sıra } \\
\text { ortalaması }\end{array}$ & $x^{2}$ & $\mathbf{p}$ & Fark \\
\hline \multirow{6}{*}{ Sporcular } & \multirow{3}{*}{ OBÖ } & 30 & $a$ & 17 & 23.06 & \multirow{3}{*}{5.379} & \multirow{3}{*}{.06} & \multirow{3}{*}{$c>a$} \\
\hline & & $31-60$ & $\mathrm{~b}$ & 12 & 30.58 & & & \\
\hline & & $61<$ & $\mathrm{C}$ & 32 & 35.38 & & & \\
\hline & \multirow{3}{*}{ DOBIFÖ } & 30 & $\mathrm{a}$ & 17 & 42.32 & \multirow{3}{*}{9.613} & \multirow{3}{*}{.00} & \multirow{3}{*}{$a>b>c$} \\
\hline & & $31-60$ & $\mathrm{~b}$ & 12 & 26.79 & & & \\
\hline & & $61<$ & $\mathrm{C}$ & 32 & 26.56 & & & \\
\hline \multirow{6}{*}{ E-spor oyuncuları } & \multirow{3}{*}{ OBÖ } & 30 & $a$ & 38 & 26.80 & \multirow{3}{*}{25.754} & \multirow{3}{*}{.00} & \multirow{3}{*}{$c>b>a$} \\
\hline & & $31-60$ & $\mathrm{~b}$ & 22 & 50.80 & & & \\
\hline & & $61<$ & $\mathrm{C}$ & 20 & 55.20 & & & \\
\hline & \multirow{3}{*}{ DOBIFÖ } & 30 & $\mathrm{a}$ & 38 & 51.72 & \multirow{3}{*}{16.968} & \multirow{3}{*}{.00} & \multirow{3}{*}{$a>b>c$} \\
\hline & & $31-60$ & $\mathrm{~b}$ & 22 & 30.40 & & & \\
\hline & & $61<$ & $\mathrm{C}$ & 20 & 30.30 & & & \\
\hline
\end{tabular}

Tablo 6'da sporcular ve e-spor oyuncuların OBÖ ve DÖBİFÖ puanları, günde dijital oyun oynama süresine göre Kuruskal Wallis Testi ile incelenmiştir. Sporcuların ve e-spor oyuncularının günde dijital oyun oynama süresine göre OBÖ ve DOBİFÖ puanlarında anlamlı farklılık saptanmıştır. Lehine anlamlı farklılık gösteren gruplar * ile gösterilmiştir. Buna göre günde 61 dakika ve üzeri oynayan sporcuların OBÖ puanları ( $\overline{\mathrm{x}}=35.38), 30$ dakika oynayanlardan $(\overline{\mathrm{x}}=23.06)$ anlamlı düzeyde yüksektir. Günde 30 dakika oynayan sporcuların DOBIFÖ puanları ( $\bar{x}=42.32), 31-60$ dakika oynayanların ( $\bar{x}=26.79)$ ile 61 dakika ve üzeri oynayanların puanlarından $(\bar{x}=26.56)$ anlamlı düzeyde yüksektir. E-spor oyuncularının OBÖ puanları incelendiğinde, 61 dakika ve üzeri oynayanların puanlarının ( $\bar{x}=55.20), 31-60$ dakika $(\bar{x}=50.80)$ ile 30 dakika ( $\bar{x}=26.80$ ) oynayanların puanlarından anlamlı düzeyde yüksek olduğu tespit edilmiştir. Ayrıca günde 30 dakika oyun oynayan e-spor oyuncularının DOBİFÖ puanları ( $\overline{\mathrm{x}}=51.72), 31-60$ dakika oyun oynayanlar $(\overline{\mathrm{x}}=30.40)$ ile 61 dakika ve üzeri oynayanların puanlarından ( $\bar{x}=30.30)$ anlamlı düzeyde yüksektir.

\section{Tartışma ve Sonuç}

Araştırma sporcuların ve e-spor oyuncularının dijital oyun bağımlılığı ve dijital oyun bağımlılığına ilişkin farkındalık düzeylerinin incelenmesini amacıyla 141 katıımcı ile gerçekleştirilmiştir. 
Araştırmanın ilk bulgusunda, araştırmaya katılan katıımcıların OBÖ ve DOBiFÖ puanlarına ilişkin toplam puanları incelenmiştir. Bu bağlamda, sporcuların oyun bağımlıığı düzeylerinin düşük, dijital oyun bağımlılığına ilişkin farkındalık puanlarının orta düzeyde olduğu saptanmışır. E-spor oyuncularının oyun bağımlılığı düzeylerinin orta, dijital oyun bağımlılı̆ına ilişkin farkındalık puanlarının yüksek düzeyde olduğu tespit edilmiştir. Buna göre e-spor oyuncularının sporculara göre yüksek düzeyde oyun bağımlılığı olması yanında oyun bağımlıı̆ı̆ına ilişkin farkındalıklarının da sporculardan yüksek olduğu tespit edilmiştir. Buna neden olarak e-spor oyuncularının dijital oyunlar üzerinde olan yetkinliğinin daha çok olması, daha fazla e-spor ile vakit geçirme potansiyelinin olması, yakinen bildikleri bu alanla alakalı bilinçlerinin daha yüksek olmasından kaynaklandığı görüşü savunulabilir. Güvendi, Tekkurşun Demir ve Keskin'in (2019) ortaokul öğrencilerinin dijital oyun bağımlılığı ve saldırganlık ilişkisini incelediği çalışmasında, katııımcıların dijital oyun bağımlıı̆ı düzeylerinin riskli grupta yer aldığı ileri sürülmüştür. Ayhan ve Köseliören, (2019), lise düzeyindeki katıımcılarla yaptığı araştırmada, katıımcıların yüzde 36.7'sinin oyun bağımlıı̆ı riski taşıdığını belirtmiştir. Ekinci, Yalçın ve Soyer (2017) lise öğrencilerinin genel olarak bazı dijital oyunlara bağımlı olduklarını belirtmiştir. Çavuş, Ayhan ve Tuncer (2016) her beş üniversite öğrencisinden birinin oyun bağımlılığı tehdidi altında bulunduğu belirtmiştir. Yaşar'ın (2019) çalışmasına katılan öğrencilerin yaklaşık yarısının dijital oyun bağımlısı olduğu saptamıştır. Sporla ilintili olan çalışmalara bakıldığında Sağlam ve Topsümer, (2019) e-spor turnuvasına katılmış olan bireyler üzerinde yaptığı çalışmada, bireylerin dijital oyunları merak ettikleri için oyun oynamaya başladıklarını, dijital oyun kültürü içerisinde yetişmiş olmalarından ötürü oyun oynadıklarını saptamıştır. Kişisel rahatlama, tatmin, sosyal ilişkilerde güven ile birlikte diğer insanlarla tanışmak, bir gruba ait olmak, liderlik etmek ve serbest zaman değerlendirme etkinliği gibi sebepler ile dijital oyunların oynandığı bilinmektedir. Dijital spor oyunlar sporcuların üst düzey bilişsel becerilerini olumlu yönde etkilediği ifade edilmektedir (Cihan ve Ilgar, 2019). Ayrıca dijital spor oyunlarının sporculara iyi bir motivasyon kaynağı ve öğrenme aracı olması gibi sporcuya kattığı olumlu özelliklerin yanında zaman kaybı, sosyalleşememe, bağımlılık gibi olumsuz özellikleri de beraberinde getirdiğini ileri sürmüşlerdir. Alan yazında dijital oyunların eğlenceli bir serbest zaman değerlendirme aracı olduğu, bireylerin bilişsel ve duyuşsal gelişimi üzerinde son derece etkili olduğu, oyunlar içine 
yerleştirilen komutları takip edebilme, el-göz koordinasyonu, motor yeteneklerde geliştirme, hatta oyunların duygusal boşalma ve gevşeme gibi olumlu yönlerinin olduğu kabul edilmektedir (Lin ve Hou, 2015; Sağlam ve Topsümer, 2019). Diğer taraftan dijital oyun oynarken aşırıya kaçılması ve davranışın tekrarlanması sonucunda ortaya çıkan oyun bağımlıı̆ının, ruhsal, fiziksel sosyal bozukluklar yaşanmasına neden olduğu ifade edilmektedir (Ayhan ve Çavuş, 2015). Ayrıca dijital oyun bağımlılığının; saldırganlık düzeyini arttırdığı, konuşmaya yönelik isteksizliğe neden olduğu, bireyi sosyal olarak kendini yaşadığı çevreden soyutlamaya ittiği, sosyal becerilerin azaldığı, kişide biyolojik bozukluklara neden olduğu, ailelerin çocuklarıyla etkili zaman geçirmesini engellediği ifade edilmektedir (Arslan ve ark., 2015; Mustafaoğlu ve Yasacı, 2018; Güvendi, Tekkurşun Demir ve Keskin, 2019). Literatür incelendiğinde, dijital oyun bağımlıı̆̆ı ile farkındalık arasında negatif yönde anlamlı bir ilişki saptanmıştır (Şehidoğlu, 2014; Çay, 2018; Keskin, 2019; Dönmez, 2018). Yaşar'a (2019) göre öğrencilerin çoğunluğu dijital oyun ve dijital oyun bağımlıı̆ına ilişkin farkındalıklara sahiptir. Hazar, Tekkurşun ve Dalkıran (2017) çalışmasında, öğrencilerin dijital oyunu 'bağımlııı' olarak algıladıklarını saptamıştır, Bu durum katııımcıların bağımlılığa ilişkin farkındalık gösterdiklerini gösterebilir. Dijital oyun bağımlıı̆ı yansıra öğrencilerin, dijital ayak izine yönelik farkındalıkların da yüksek düzeyde olduğu saptanmıştır (Sürmelioğlu ve Seferoğlu, 2019).

Araştırmanın ikinci bulgusunda dijital oyun bağımlılığı ve dijital oyun bağımlıı̆ı̆ı ilişkin farkındalık puanları arasında negatif yönde yüksek düzeyde anlamlı ilişki saptanmıştır. Bu bağlamda düzenli dijital oyun oynayan e-spor oyuncularının ve sporcuların bağımlılık düzeyleri arttıkça dijital oyun bağımlıı̆̆ına ilişkin farkındalıklarının düştüğü saptanmıştır. Başka bir değişle, dijital oyun bağımlıı̆ına ilişkin farkındalıkları yüksek olan bireyler bağımlıık durumundan kaçınabilmekte oldukları varsayılabilir. Bağımlııı seviyelerinin yüksek olması fakat farkındalıklarının düşük olmasının sebebi; katıımcıların oyun oynadıklarında aşırı odaklanmış olmaları, eğlenme güdülerin artması, gerçek yaşamdan oyun vasıtasıyla uzaklaşarak hareketsiz yaşama alışkanlığı edinmeleri gösterilebilir. Ayrıca dijital oyun oynama davranışı geliştiren bireylerin, oyun oynarken içsel, dışsal motivasyon kaynaklarının üst düzeye ulaşmasından dolayı, dijital oyun bağımlılı̆ına ilişkin farkındalık düzeylerinin engellemiş olma intimali olası bir durumdur. Kneer ve arkadaşları (2014) çalışmalarında, dijital oyun bağımlıı̆ı ve risk faktörleri hakkında 
farkındalığın, oyuncular ve danışmanlar arasında yüksek olduğunu saptamışlardır. Hundley ve Shyles'in (2010) dijital teknoloji ile alakalı ergen bireylerin algılarını ve farkındalıklarını incelediği çalışmasında, katılımcıların çevrimiçi riskleri ve bireye zarar verebilecek durumları bilmediği, buna tepki göstermediği ve katılımcıların rahat tutumları olduğu saptanmıştır. Bu durum karşısında Hundley ve Shyles'in (2010) kaygılandığı görülmüştür. Ayrıca çevrimiçi kullanımla alakalı katılımcıların çok az ahlaki endişe duyduklarını da tespit etmişlerdir. Ebeveynlerin ise, bilişim çağının gerekleri içinde dijital oyun bağımlılıkların farkında olduğu tespit edilmiştir (Aydoğdu Karaaslan, 2015). Hsu ve Chiou (2011), öğretmen adaylarının aşırı oyun oynamanın bazı olumsuz etkileri olabileceğine dair farkındalıkları olmasına rağmen, çoğunluğunun dijital oyunlar oynadığı ve dijital oyunların öğrenciler için faydalı bir araç olabileceğine inandıklarını ifade etmişlerdir. Karademir Coşkun ve Filiz (2019), öğretmen adaylarının dijital oyun bağımlılığına yönelik farkındalıklarının incelendiği çalışmada, öğretmen adaylarının bireyi oyun bağımlıı̆̆ına götüren faktörler arasında neden sonuç ilişkisi kurabildiğini, çeşitli çıkarımla yapabildiklerini, oyun bağımlılığına götüren nedenler konusunda genel bir bilgiye sahip olduklarını ve bu bilgileri gözlem yoluyla edindiklerini belirlemiştir. Gençlerin teknolojik ortamlar için benzersiz bir kitle olduğunu ve teknoloji kullanım alışkanlıklarının farklı olabileceğini savunan Jordan ve ark. (2007), aynı zamanda gençlerin dijital teknoloji hakkında algı ve bilincini araştırmak için çok az çaba harcandığını iddia etmişlerdir.

Araştırmanın diğer bulgusunda sporcuların yaşı ile dijital oyun bağımlılığı puanı ve dijital oyun bağımlılığına ilişkin farkındalık puanları incelenmiş, anlamlı ilişki tespit edilmiştir. Sporcuların yaşı ile OBÖ puanı arasında pozitif yönde orta düzeyde DÖBIFÖ puanı arasında negatif yönde orta düzeyde anlamlı ilişki tespit edilmesidir. Buna göre sporcu katıımcıların yaşı arttıkça dijital oyun bağımlııı düzeyleri artarken, oyun bağımlıığına ilişkin farkındalıklarının azaldığı görülmüştür. Sosyal bir varlık olan insanın yaşı ilerledikçe çevresinin daralma durumundan ötürü yaşı ilerlemiş bireylerin kendilerine sanal bir dünya yaratma isteklerinin artabileceğinin bu duruma sebep olmuş olabileceği söylenebilir. Günümüzde sporcuların yaşları arttıkça spor hayatındaki sorumluklarının antrenman, egzersiz gibi olgulardan dolayı artması, yorgun zamanlarda bile kolayca dijital oyuna ulaşmaları, yaşın artması ile çevreye duyulan güvensizliğin artması ve yalnız kalınan sıkıcı zamanları oyun ile değerlendirme davranışı geliştirmeleri, onların dijital oyun bağımlılığının artmasına 
neden olmuş olabilir. Çalışma bulgularının aksine yaş arttıkça dijital oyun bağımlıı̆ı düzeyinin azaldığını tespit eden çalışmalar bulunmaktadır (Ünübol ve ark., 2020). Bu durumun sebebi olarak, dijital ortamlardaki oyunların yaş ayırt etmeksizin tüm bireylere hitap ettiğini ve bireylerin ilgilerine göre oyunların çeşitlilik göstermesinden kaynaklandığını söylenebilir (Kılıç, 2020).

E-spor oyuncularının cinsiyetlerine göre dijital oyun bağımlılığı puanları arasında anlamlı farklılık saptanmıştır. Saptanan bu farklıık, erkek e-spor oyuncularının dijital oyun bağımlıı̆ı düzeylerinin, kadın e-spor oyuncularının dijital oyun bağımılıı̆ı düzeyinden anlamlı düzeyde yüksek olmasıdır. Erkeklerin bireysel grup halindeki oyunlara daha yatkın olmaları sebebiyle boş zamanlarını genellikle bu alanda değerlendirmeyi seçmiş olabilecekleri düşünülebilir. Araştırma bulgularıyla benzerlik gösteren erkeklerin dijital oyun bağımlııklarının kadınlara göre anlamlı düzeyde farklılaştığını tespit eden çalışmalar bulunmaktadır (van Rooij ve ark., 2014; Çavuş, Ayhan ve Tuncer, 2016; Hazar ve ark., 2017; Güvendi, Tekkurşun Demir ve Keskin, 2019; Ayhan ve Köseliören, 2019). Çalışmalar özellikle 10-19 yaş arasındaki erkek ergenlerin aşırı oyun oynama ve problemli kullanım yatkınlığı olduğunu göstermektedir (Irmak ve Erdoğan, 2016). Diğer taraftan kadın ve erkek bireylerin dijital oyun bağımlılığı düzeyleri arasında anlamlı farklılık saptamayan çalışmalar da mevcuttur (Kim ve ark., 2008).

Araştırma değişkenlerinden zararlı alışkanlığa sahip olma durumu ile katılımcıların dijital oyun bağımlıı̆ı puanı ve dijital oyun bağımlıı̆ına ilişkin farkındalık puanlarını arasında anlamlı farklıık saptanmamıştır. Kelley ve Berridge (2002) oyun oynama davranışının, alkol ve uyuşturucuların yaptığının aksine beyindeki nörobiyolojik süreçleri doğrudan etkileyemiyor olduğunu bu yüzden, bağımlıı̆ın ortaya çıkmasının imkânsız olabileceğini ileri sürmüştür. Hellman ve arkadaşları (2013), çevrimiçi oyun oynama davranışının madde bağımılı̆̆ından büyük ölçüde farklı olabileceğini ifade etmiştir. Çalışma bulgularının aksine Spekman ve arkadaşları (2013) oyun bağımlılığı ile psikopatolojik kişilik özelliği ilişkisini incelediği çalışmada, madde kullanım bozukluğu ve problemli internet kullanımı ile psikopatolojik kişilik özellikleri arasında anlamlı ilişki olduğu sonucuna ulaşmışlardır. Walther ve arkadaşları (2012), bilgisayar oyunları, problemli kumar ve madde kullanımının ortak özelliklerini araştırmış ve dijital oyun oynama ile zararı alışkanlık kullanımı arasında pozitif yönlü anlamlı ilişki tespit etmiştir. Van Rooij ve arkadaşları 
(2014) sigara, alkol, uyuşturucu gibi madde kullanımları ile problemli oyun oynama davranışı arasında olumlu ilişki tespit etmiştir. Ünübol ve arkadaşları da (2020) madde kullanımının problemli oyun davranışıyla pozitif yönlü bir ilişki içerisinde olduğunu saptamışlardır. Hazar, Tekkurşun ve Dalkıran (2017) öğrencilerin geleneksel ve dijital formdaki oyuna yönelik algılarının incelendiği çalışmada, uyuşturucu, hastalık gibi algıların ön plana çıktığını ve bağımlılık imgesinin oldukça yoğun tercih edildiğini belirtmişlerdir. Yaşar (2019) çalışmasında katılımcıların çoğunluğunun dijital oyun bağımlıı̆ıını sigara, alkol ve uyuşturucu maddeye benzettiğini ileri sürmüştür.

Araştırmanın son bulgusu olarak katılımcıların günlük dijital oyun oynama süresine göre dijital oyun bağımlıı̆ı ile dijital oyun bağımlıı̆ı̆ına ilişkin farkındalık puanlarında anlamlı farklılık saptanmıştır. Günde 61 dakika ve üzeri dijital oyun oynayan sporcuların bağımlılık puanları, günde 30 dakika dijital oyun oynayan sporculardan anlamlı düzeyde yüksektir. Günde 30 dakika dijital oyun oynayan sporcuların dijital oyun bağımlılığına ilişkin farkındalık puanları, 31-60 dakika oynayanların ile 61 dakika üzeri oynayanların puanlarından anlamlı düzeyde yüksektir. Bu bağlamda sporcuların dijital oyun oynama süreleri arttıkça bağımlılıklarının yükseldiği, diğer taraftan ise dijital oyun bağımlıı̆ına ilişkin farkındalıklarının düştüğü söylenebilir. E-spor oyuncularının dijital oyun bağımlıı̆̆ı puanları incelendiğinde, 61 dakika ve üzeri oynayanların puanlarının, 31-60 dakika 30 dakika oynayanların puanlarından anlamlı düzeyde yüksek olduğu tespit edilmiştir. Ayrıca günde 30 dakika oynayan e-spor oyuncularının dijital oyun bağımlıı̆ına ilişkin farkındalık puanları, 31-60 dakika oynayanların ile 61 dakika ve üzeri oynayanların puanlarından anlamlı düzeyde yüksektir. Sporcu katılımcılarla benzerlik göstererek, e-sporcuların dijital oyun oynama süreleri arttıkça bağımlılıklarının yükseldiği buna karşın dijital oyun bağımlıı̆ına ilişkin farkındalıklarının düştüğü söylenebilir. Kişilerin eğlence arayışı, meydan okuma amacı, serbest zamanı değerlendirmek istemesi, bulunduğu ortamdan uzaklaşma isteği, gerçek yaşamda yapamadıklarını sanal ortamda gerçekleştirme arzusu, zamanı akıcı halde geçirme isteği, çevrimiçi sosyal etkileşim kurma imkânına sahip olma arzusu, oyuncuların kendilerinin ideal olduğunu düşündükleri yönleri deneyebilme imkanları elde edebilmek gibi isteklerin yansıra kişilerin oyunu modern bir uğraş olarak görmeleri de dijital oyuna katılma nedenleri arasında gösterilebilir 
(Tekkurşun Demir ve Mutlu Bozkurt, 2019; Sağlam ve Topsümer, 2019; Bhagat, Jeong ve Kim, 2020). Bireyler dijital ortam içinde çifte bir hayat kurabilir, sosyal etkileşim için kendi ideal karakterlerini yaratabilir, yeni arkadaşlar bulabilir ve seçtikleri uzun vadeli sosyal gruplarla ilişkilerini geliştirebilirler (Kneer ve ark., 2014). Tüm bu nedenler neticesinde, bireylerin dijital oyun oynama sürelerinin artış göstermesiyle bağımlılık risklerinin de artış göstereceği söylenebilir. Nitekim çalışma bulguları bu kanıyı destekler niteliktedir. Çalışma bulgularıyla benzer şekilde, 60 dakika ve üzeri günlük dijital oyun oynayan bireylerin bulunduğu çalışmalar mevcuttur (Ayhan ve Köseliören, 2019). Ayrıca çalışma bulgularına paralel olarak dijital oyun oynama süresi arttıkça dijital oyun bağımlıı̆ının artı̧̧ gösterdiğini tespit eden çalışmalar vardır (Hazar ve ark., 2017; Kılıç, 2020). Ailelerde kullanım süresinin artışının bağımlıığa yol açtığı inancına sahiptirler (Mustafaoğlu ve Yasacı, 2018). Dijital oyun süresi artıkça kişinin bu oyunlara olan ilgi ve alakasının artması ile dijital oyuna ayrılan zaman gün geçtikçe artabilir bu da bağımlılık olgusunu yanında getirebilir (Güvendi ve ark., 2019). Bozkurt, Dursun ve Arı (2019) çalışmasında dijital oyun oynama süresi arttıkça dijital oyun oynama tutumunda artış olduğunu ifade etmiştir. Bağımlılık durumunda kontrolsüz oyun oynama durumu göz önünde bulundurulursa öğrencilerin oynadıkları süre farkındalıklarının az olduğu söylenebilir (Yaşar, 2019). Nitekim van Rooij (2011) çağımız içerisindeki ergenlerin bir oyun kuşağı olduklarını dahası internet ve video oyunları olmayan bir dünyanın varığııın farkında olmadıklarını ifade etmektedir.

Araştırma bulguları sonucunda oyun bağımlılığı düzeyi açısından araştırmaya katılan sporcuların puanlarının düşük, e-spor oyuncularının puanlarının orta düzeyde olduğu, dijital oyun bağımlıı̆̆ına ilişkin farkındalık düzeyi açısından sporcuların puanlarının orta, e-spor oyuncularının puanlarının ise yüksek olduğu görülmüştür. Oyun bağımlıı̆ı ile dijital oyun bağımlıığına ilişkin farkındalık puanları arasında anlamlı düzeyde negatif yönde ilişki olduğu sonucuna varılmıştır. Sporcuların yaşı ile OBÖ puanı arasında pozitif yönde orta düzeyde DÖBIFÖ puanı arasında negatif yönde orta düzeyde anlamlı ilişki olduğu sonucuna varılmıştır. Dijital oyun bağımlılığı puanlarının erkek e-spor oyuncularının lehine olduğu tespit edilmiştir. Zararlı alışkanlık davranışı ile OBÖ ve DOBIFÖ arasında farklııı bulunmamıştır. E-spor oyunlarına katıım süresi yüksek olan sporcu ve e-spor oyuncularının, OBÖ 
puanlarının yüksek olduğu, oyun süresi az olan sporcu ve e-spor oyuncularının DOBIFÖ puanlarının yüksek olduğu sonucuna varılmıştır.

\section{Öneriler}

Teknolojik bir çağda yaşamakta olduğumuz ve oyunun geleneksel formunun değişiyor olması göz önünde bulundurulduğunda, bireylerin potansiyel bağımlılık durumlarına ilişkin bilinçlendirme eğitimleri almaları önem kazanmaktadır. Bu sayede bireylerin dijitalleşen ortamlardan bir tanesi olan oyun hakkında farkındalık düzeylerinin geliştirilmesine sağlanabilir. Dikkat çeken araştırma bulgularından bir tanesi fiziksel sporlarla uğraşan bireylerin bağımlılık puanlarının düşük olmasıdır. Bu sonuç ışığında, bireylerin dijital oyun bağımlılıklarından uzaklaşması adına fiziksel oyunlara yönlendirmeleri önerilebilir. Ayrıca dijital oyun oynamaktan geri duramayan bireylere, fiziksel hareketlilik içeren oyunların önerilmesiyle, bireylerin hareketli yaşama geçmeleri sağlanabilir. Buna ek olarak, çalışma kapsamında veriler toplanırken öz değerlendirme yöntemi kullanıldığından ötürü gelecek çalışmalarda yöntemin ve örneklem grubunun çeşitlendirilerek güncellenmesi önerilebilir.

\section{Kaynaklar}

Akın, A., Usta, F., Başa, E., \& Özçelik, B., (2016). Oyun Bağımlılığı Ölçeği'nin Türkçeye Uyarlanması, Geçerlik ve Güvenirlik Çalışması. Türkiye Sosyal Araştırmalar Dergisi, 20(1), 223-232.

Arslan, A. (2019). Ortaöğretim Öğrencilerinin Dijital Bağımlılık Düzeylerinin Çeşitli Değişkenler açısından İncelenmesi: Sivas İli Örneği. Gazi Eğitim Bilimleri Dergisi, 5(2), 63-80. Doi://Dx.Doi.Org/10.30855/Gjes.2019.05.02.004

Arslan, A., Kırık, A. M., Karaman, M., \& Çetinkaya, A. (2015). Lise ve Üniversite Öğrencilerinde Dijital Bağımlılık. Iletişim ve Edebiyat Araştırmaları Dergisi, 8, 34-58.

Aydoğdu Karaaslan, İ. (2015). Dijital Oyunlar ve Dijital Şiddet Farkındalığı: Ebeveyn ve Çocuklar Üzerinde Yapılan Karşılaştırmalı Bir Analiz. Journal Of International Social Research, 8(36). 
Ayhan, B., \& Çavuş, S. (2014). Computer Game Addıctıon: A Fıeld Study On Adolescents, 12. International Symposium Communication In The Millennium. 15-18 June, Eskişehir, Ss. 197-208.

Ayhan, B., \& Çavuş, S. (2015). Online Game Addiction Among High School Students. C. Daba-Buzoianu \& H. Arslan (Dü) İçinde, Contextual Approaches İn Communication, (85-93). Frankfurt: Peterlang Academic Research.

Ayhan, B., \& Köseliören, M. (2019). İnternet, Online Oyun ve Bağımlılık. Online Journal Of Technology Addiction And Cyberbullying, 6(1), 1-30.

Bhagat, S., Jeong, E. J., \& Kim, D. J. (2020). The Role Of Individuals' Need For Online Social Interactions And Interpersonal Incompetence In Digital Game Addiction. International Journal Of Human-Computer Interaction, 36(5), 449463.

Bozkurt, T. M., Dursun, M., \& Arı, Ç. (2019). Examination Of Attitudes Of Students Of Sports Sciences Towards Digital Game Play. Journal Of Human Sciences, 16(4), 1217-1227.

Brown, K. W., Ryan, R. M., \& Creswell, J. D. (2007). Mindfulness: Theoretical foundations and evidence for its salutary effects. Psychological Inquiry, 18(4), 211- 237. Doi: 10.1037/0022-3514.84.4.822.

Can, H. C., \& Tozoğlu, E. (2019). Üniversite Öğrencilerinin İnternet Bağımlılık Düzeylerinin Spor ve Farklı Değişkenler Açısından İncelenmesi. Spor Eğitim Dergisi, 3(3), 102-118.

Campbell, W. G. (2003). Addiction: A Disease Of Volition Caused By Cognitive Impairment. The Canadian Journal Of Psychiatry, 48(10), 669-674.

Cihan, BB., \& Ilgar, EA. (2019). Dijital Spor Oyunlarının Sporcular Üzerindeki Etkilerinin İncelenmesi: Fenomenolojik Bir Çözümleme. Gaziantep Üniversitesi Spor Bilimleri Dergisi, 4(1), 171-189.

Çavuş, S., Ayhan, B., \& Tuncer, M. (2016). Bilgisayar Oyunları ve Bağımlıık: Üniversite Öğrencileri Üzerine Bir Alan Araştırması. İletişim Kuram ve Araştırma Dergisi, (43).

Çay, E. (2018). Ergenlerde internet bağımlılığının sosyal duygusal sağlık ve bilinçli farkındalık düzeylerine etkisi. Yüksek Lisans Tezi. https://tez.yok.gov.tr sayfasından erişilmiştir. 
Demir, G. T., \& Cicioğlu, H. İ. (2020). Dijital Oyun Bağımlılığına İlişkin Farkındalık Ölçeği (Dobifö): Geçerlik ve Güvenirlik Çalışması. Avrasya Spor Bilimleri Ve Egitim Dergisi, 2(1), 1-17.

Demir, G. T., \& Bozkurt, T. M. (2019). Dijital oyun oynama tutumu ölçeği (DOOTÖ): Geçerlik ve güvenirlik çalışması. Sportif Bakış: Spor ve Eğitim Bilimleri Dergisi, 6(1), 1-18.

Demir, G. T., \& Hazar, Z. (2018). Dijital Oyun Oynama Motivasyonu Ölçeği (Doomö): Geçerlik ve Güvenirlik Çalışması. Journal Of Physical Education \& Sports Science/Beden Egitimi ve Spor Bilimleri Dergisi, 12(2).

Dönmez, Ş. (2018). Çevrimiçi Oyun Bağımlıı̆ının Bilinçli Farkındalık ve Yaşam Doyumu ile İlişkisi. Yüksek Lisans Tezi. https://tez.yok.gov.tr sayfasından erişilmiştir.

Ekinci, N. E., Yalçın, I., \& Soyer, F. (2017). Digital Game Addiction Level Of High School Students İn Turkey. Acta Kinesologica, 11(2), 98-103.

Frölich, J., Lehmkuhl, G., Orawa, H., Bromba, M., Wolf, K., \& Görtz-Dorten, A. (2016). Computer game misuse and addiction of adolescents in a clinically referred study sample. Computers in Human Behavior, 55, 9-15.

Gökşen, C. (2014). Oyunların Çocukların Gelişimine Katkıları ve Gaziantep Çocuk Oyunları. Atatürk Üniversitesi Türkiyat Araştırmaları Enstitüsü Dergisi, 52, 229259.

Güvendi, B., Tekkurşun Demir, G., \& Keskin, B. (2019). Ortaokul Öğrencilerinde Dijital Oyun Bağımlıığı ve Saldırganlık. Opus Uluslararası Toplum Araştırmaları Dergisi, 11 (18), 1194-1217. Dol: 10.26466/Opus.547092

Güvenli İnternet Merkezi [GIM], (2019). Dijital Oyunlar Raporu.

Https:/Nww.Gunliweb.Org.Tr/ Adresinden 29.06.2020 Tarihinde Erişilmiştir.

Hauge, M. R., \& Gentile, D. A. (2003, April). Video Game Addiction Among Adolescents: Associations With Academic Performance And Aggression. Poster Presented At Society For Research In Child Delopment Conferance, Tampa, FL Hazar, Z., Demir, G.,Namlı, S., \& Türkeli, A. (2017). Ortaokul Öğrencilerinin Dijital Oyun Bağımlıı̆ğı ve Fiziksel Aktivite Düzeyleri Arasındaki İlşkinin İncelenmesi. Niğde Üniversitesi Beden Eğitimi ve Spor Bilimleri Dergisi, 11(3), 320-332. 
Can, H.C. ve Tekkurşun Demir, G. (2020). Sporcuların ve E-spor Oyuncularının Dijital Oyun Bağımlılığı ve Dijital Oyun Bağımlılığına İliş̧kin Farkındalık Düzeyleri. Gaziantep Üniversitesi Spor Bilimleri Dergisi, 5(4), 364-384.

Hazar, Z., Tekkurşun, D. G., \& Dalkıran, H. (2017). Ortaokul öğrencilerinin geleneksel oyun ve dijital oyun algılarının incelenmesi: Karşılaşıımalı metafor çalışması. Spormetre Beden Eğitimi ve Spor Bilimleri Dergisi, 15(4), 179-190.

Hellman, M., Schoenmakers, T. M., Nordstrom, B. R., \& van Holst, R. J. (2013). Is there such a thing as online video game addiction? A cross-disciplinary review. Addiction Research \& Theory, 21(2), 102-112.

Hsu, T.Y., \& Chiou, G.F. (2011). Preservice Teachers' Awareness Of Digital GameSupported Learning. In M. Koehler \& P. Mishra (Eds.), Proceedings Of SITE 2011--Society For Information Technology \& Teacher Education International Conference (Pp. 2135-2141).

Huizinga, J. (2018). Homo Ludens/Oyunun Kültürel İşlevi Üzerine Bir İnceleme. Çev. I. Mutlu, İstanbul: Dorlion.

Hundley, H. L., \& Shyles, L. (2010). US Teenagers' Perceptions And Awareness Of Digital Technology: A Focus Group Approach. New Media \& Society, 12(3), 417-433.

Irmak, A. Y., \& Erdoğan, S. (2016). Ergen ve Genç Erişkinlerde Dijital Oyun Bağımlıığı: Güncel Bir Bakış. Türk Psikiyatri Dergisi, 27(2), 128-137.

İlhan, E. L., \& Esentürk, O. K. (2015). Zihinsel Engelli Bireylerde Sporun Etkilerine Yönelik Farkındalık Ölçeği (ZEBSEYFÖ) Geliştirme Çalışması. CBÜ Beden Eğitimi ve Spor Bilimleri Dergisi, 9(1), 19-36.

Jordan, A., Trentacoste, N., Henderson, V., Manganello, J., \& Fishbein, M. (2007). Measuring the time teens spend with media: Challenges and opportunities. Media Psychology, 9(1), 19-41.

Karademir Coşkun, T., \& Filiz, O. (2019). Okul Öncesi Öğretmen Adaylarının Dijital Oyun Bağımlıı̆ı̆na Yönelik Farkındalıkları. Addicta: The Turkish Journal On Addictions, 6, 239-267. Http://Dx.Doi.Org/10.15805/Addicta.2019.6.2.0036 Karasar, N. (2011). Bilimsel Araştırma Yöntemleri. Ankara: Nobel.

Kelley A., \& Berridge K. (2002). The neuroscience of natural rewards: Relevance to addictive drugs. The Journal of Neuroscience, 22: 3306-2211.

Keskin, B. (2019). Ortaokul Öğrencilerinin Dijital Oyun Bağımlılı̆ı ile Psikolojik Sağlamlık ve Bilinçli Farkındalık Düzeyleri Arasındaki İlişkinin İncelenmesi. Yüksek Lisans Tezi. https://tez.yok.gov.tr sayfasından erişilmiştir. 
Kılıç, M. A. (2020). 15-18 Yaş Arası Okul Sporlarına Katılan Öğrencilerin Dijital Oyun Bağımlıı̆ı ile Sosyal ve Duygusal Yalnızlık Düzeylerinin İncelenmesi. Yüksek Lisans Tezi. https://tez.yok.gov.tr sayfasından erişilmiştir.

Kibar, Ö. H. (2019, Haziran). "Farkındayız" Projesi 40 Bin Gence Ulaştı. Anadolu Haber Ajansı. Www.Aa.Com.Tr Adresinden 27.06.2020 Tarihinde Erişilmiştir.

Kim, E. J., Namkoong, K., Ku, T., \& Kim, S. J. (2008). The Relationship Between Online Game Addiction And Aggresion, Self-Control And Narcissistic Personality Traits. European Psychiatry, 23, 212-218.

Kneer, J., Rieger, D., Ivory, J.D., \& Ferguson, C. (2014). Awareness Of Risk Factors For Digital Game Addiction: Interviewing Players And Counselors. Int J Ment Health Addiction 12, 585-599. Https://Doi.Org/10.1007/S11469-014-9489-Y

Lin, Y. H., \& Hou, H. T. (2015). Exploring Young Children's Performance On And Acceptance Of An Educational Scenario-Based Digital Game For Teaching Route-Planning Strategies: A Case Study. Interactive Learning Environments, 1-14.

Marsh, J., Plowman, L., Yamada-Rice, D., Bishop, J., \& Scott, F. (2016) Digital Play: A New Classification. Early Years, 36(3), 242-253, Doi: 10.1080/09575146.2016.1167675.

Mustafaoğlu, R., \& Yasacı, Z., (2018). Dijital Oyun Oynamanın Çocukların Ruhsal ve Fiziksel Sağlığı Üzerine Olumsuz Etkileri. Bağımlılık Dergisi, No.3, 51-58.

Mustola, M., Koivula, M., Turja, L., \& Laakso M.L., (2016) Reconsidering Passivity And Activity In Children' S Digital Play. New Media Society. Doi:10.1177/1461444816661550.

Müller, K. W., Janikian, M., Dreier, M., Wölfling, K., Beutel, M. E., Tzavara, C. \& Tsitsika, A. (2015). Regular gaming behavior and internet gaming disorder in European adolescents: results from a cross-national representative survey of prevalence, predictors, and psychopathological correlates. European Child \& Adolescent Psychiatry, 24(5), 565-574.

Namlı, S., \& Demir, G. T. (2020). The Relationship between Attitudes towards Digital Gaming and Sports. Turkish Online Journal of Educational TechnologyTOJET, 19(1), 40-52. 
Sağlam, M., \& Topsümer, F. (2019). “Üniversite Öğrencilerinin Dijital Oyun Oynama Nedenlerine İlişkin Nitel Bir Çalışma”. Akdeniz Üniversitesi İletişim Fakültesi Dergisi, (AKIL) Aralık (32), S. 485-504

Sağlık Bakanlığı, (2018). Dijital Oyun Bağımııı̆̆ı Çalıştayı, Sonuç Raporu. Www.Gunliweb.Org.Tr Adresinden 30.06.2020 Tarihinde Erişilmiştir.

Shaw, M., \& Black, D. W. (2008). Internet Addiction: Definition, Assessment, Epidemiology, And Clinical Management. CNS Drugs, 22(5), 353-365.

Spekman, M. L., Konijn, E. A., Roelofsma, P. H., \& Griffiths, M. D. (2013). Gaming addiction, definition and measurement: A large-scale empirical study. Computers in Human Behavior, 29(6), 2150-2155.

Sürmelioğlu, Ö.G.Y., \& Seferoğlu, S.S. (2019). Yükseköğretim Öğrencilerinin Dijital Ayakizi Farkındalık ve Yaşantılarının İncelenmesi. World Journal on Educational Technology: Current Issues, 11(1), 48-64.

Şehidoğlu, Z. (2014). 15-17 yaş grubu ergenlerde bilinçli farkındalık düzeyi ile problemli internet kullanımı arasındaki ilişkinin incelenmesi. Yüksek Lisans Tezi. https://tez.yok.gov.tr sayfasından erişilmiştir.

Tarhan, N., \& Nurmedov, S. (2011). Bağımlıık: Sanal Ya Gerçek. İstanbul: Timaş Yayınları.

Ünübol, H., Koç, A. Ş., Sayar, G. H., Stavropoulos, V., Kircaburun, K., \& Griffiths, M. D. (2020). Measurement, profiles, prevalence, and psychological risk factors of problematic gaming among the Turkish community: a large-scale national study. International Journal of Mental Health and Addiction, 1-21.

van Rooij, A.J. (2011). Online Video Game Addiction: Exploring a New Phenomenon. Erasmus University Rotterdam. Retrieved from http://hdl.handle.net/1765/23381 van Rooij, A. J., Kuss, D. J., Griffiths, M. D., Shorter, G. W., Schoenmakers, T. M., \& Van De Mheen, D. (2014). The (co-) occurrence of problematic video gaming, substance use, and psychosocial problems in adolescents. Journal of behavioral addictions, 3(3), 157-165.

Yalçın Irmak, A., \& Erdoğan, S. (2016). Ergen ve Genç Erişkinlerde Dijital Oyun Bağımlıı̆̆ı: Güncel Bir Bakış, Türk Psikiyatri Dergisi: 27, 128-137. Http:/Nww.Turkpsikiyatri.Com/PDF/ C27S2/07.Pdf 
Can, H.C. ve Tekkurşun Demir, G. (2020). Sporcuların ve E-spor Oyuncularının Dijital Oyun Bağımlılığı ve Dijital Oyun Bağımlılığına İlişkin Farkındalık Düzeyleri. Gaziantep Üniversitesi Spor Bilimleri Dergisi, 5(4), 364-384.

Yaşar, S. K. (2019). Ortaokul Öğrencilerinin Gözünden Dijital Oyun ve Dijital Oyun Bağımlıı̆̆ı: Kocaeli Illi Örneği. Yüksek Lisans Tezi. https://tez.yok.gov.tr sayfasından erişilmiştir.

Young, K. S. (2009). Understanding Online Gaming Addiction And Treatment İssues For Adolescents. The American Journal Of Family Therapy, 37(5), 355- 372.

Walther, B., Morgenstern, M., \& Hanewinkel, R. (2012). Co-occurrence of addictive behaviours: Personality factors related to substance use, gambling and computer gaming. European Addiction Research, 18(4), 167-174. doi:

$10.1159 / 00033566$ 